\title{
Treadmill exercise alleviates stress-induced anxiety-like behaviors in rats
}

\author{
Jin-Hee Seo* \\ Department of Adaptive Physical Education, Baekseok University, Cheonan, Korea
}

Stress is the physiological responses of organisms to harmful or threatening stimuli that allow appropriate behavioral responses to the stressor. In the present study, the effect of treadmill exercise on stress-induced anxiety was evaluated using rats. To induce stress, the rats were exposed to an inescapable electric foot shock. Exposure of rats to the electric foot shock was performed for 7 days. The rats in the exercise groups were made to run on a motorized treadmill for 30 min once a day for 4 weeks stating one day after last electric food shock. Anxiety-like behaviors were determined by open field test and elevated plus-maze test. The expressions of c-Fos and neuronal nitric oxide synthase (nNOS) in the hypothalamus and locus coeruleus were detected by immunohistochemistry. In the present results, locomotor activity in the center of the open field test and the number of entries and time in the open arms of the elevated plus-maze test were reduced in the rats with stress-induced anxiety. Treadmill running enhanced these locomotor activities, the number of entries and time in the stress-induced anxiety rats. c-Fos and nNOS expressions in the hypothalamus and locus coeruleus were increased in the stress-induced rats. Treadmill exercise reduced c-Fos and nNOS overexpressions in the stress-induced rats. In the present study, treadmill exercise ameliorated anxiety-like behaviors in the stress-induced rats. The improving effect of treadmill exercise on anxiety-like behaviors might be ascribed to the suppressing effect of exercise on c-Fos and nNOS expressions.

Keywords: Stress, Anxiety, Treadmill exercise, c-Fos, Neuronal nitric oxide synthase

\section{INTRODUCTION}

Stress is the physiological responses of organisms to harmful or threatening stimuli that allow appropriate behavioral responses to the stressor. If the organism could not adapt to stress, adaptive physiological responses are converted into the maladaptive pathological conditions (Borodovitsyna et al., 2018). Several interconnected brain areas are involved in the control of stress and anxiety. Especially, locus coeuleus, amygdala, and hypothalamic-pituitary-adrenal (HPA) system are the key components in the control of stress and anxiety (Adhikari, 2014). The locus coeuleus is the major central noradrenergic nucleus and coordinates behavioral and autonomic responses related to anxiety, fear, and stress (Berridge and Waterhouse, 2003). The hypothalamic paraventricular nucleus regulates activity of the HPA axis and connects the brain to the neuroendocrine stress response system (Herman and Tasker,
2016). Dysregulation of these brain areas increases the risk for anxiety- and stress-related disorders (Myers et al., 2017).

The transcription factor c-Fos is rapidly induced in response to cellular activity, and c-Fos regulates expression of multiple target genes. c-Fos is increased in various brain regions of mice and rats exposed to chronic stress, especially in the paraventricular nucleus of the hypothalamus (Imaki et al., 2003). Therefore, induction of c-Fos has been used as an indicator of neuronal activation in the key areas, paraventricular nucleus and locus coeuleus. c-Fos is specifically linked to neuronal plasticity, long-term potentiation, and synapse formation, and alterations in synaptic connectivity could be an underlying mechanism that leads to long-term changes in emotionality following acute stress exposure (Minatohara et al., 2016; Ploski et al., 2011).

Nitric oxide synthase (NOS) regulates regional neuronal activation depending upon the stimulus (Sherwin et al., 2017). Nitric
${ }^{*}$ Corresponding author: Jin-Hee Seo (iD https://orcid.org/0000-0003-2766-1282 Department of Adaptive Physical Education, Baekseok University, 76 Munam-ro, Dongnam-gu, Cheonan 31065, Korea

Tel: +82-41-550-2207, Fax: +82-41-550-2990, E-mail: sjh0521@bu.ac.kr

Received: September 7, 2018 / Accepted: October 8, 2018
This is an Open Access article distributed under the terms of the Creative Commons Attribution Non-Commercial License (http://creativecommons.org/licenses/by-nc/4.0/) which permits unrestricted non-commercial use, distribution, and reproduction in any medium, provided the original work is properly cited. 
oxide (NO) is synthesized by a number of NOS isoenzymes, which catalyze the oxidation of $\mathrm{L}$-arginine to $\mathrm{NO}$ and citrulline. NOS is implicated in the anxiety-associated behaviors (Miguel and Nunes-de-Souza, 2008; Workman et al., 2008). There are three isoforms of NOS: neuronal NOS (nNOS), endothelial NOS and inducible NOS. nNOS overexpression in the hippocampus is essential for chronic stress-induced depression and inhibition of $\mathrm{nNOS}$ signaling in the brain may represent a novel approach for the treatment of depressive disorders (Zhou et al., 2007).

Regular exercise improves mental health for individuals with anxiety disorders (Asmundson et al., 2013; Hovland et al., 2013; Merom et al., 2008). However, a little information is available regarding the effect of treadmill exercise on the stress-induced anxiety disorder. In the present study, the effect of treadmill exercise on stress-induced anxiety focusing on the expressions of c-Fos and $\mathrm{nNOS}$ was investigated using rats.

\section{MATERIALS AND METHODS}

\section{Experimental animals and treatments}

The experimental procedures were performed in accordance with the animal care guidelines of the National Institutes of Health and the Korean Academy of Medical Sciences. Male Sprague-Dawley rats, weighing $100 \pm 5$ g (5 weeks old), were used in this experiment (Orient Co., Seoul, Korea). Each animal was housed under controlled temperature $\left(20^{\circ} \mathrm{C} \pm 2^{\circ} \mathrm{C}\right)$ and lighting (07:00 a.m. to 19:00 p.m.) conditions with food and water made available ad libitum. The animals were randomly divided into 4 groups ( $\mathrm{n}=9$ in each group): the control group, the exercise group, the stress-induced group, and the stress-induced and exercise group.

\section{Induction of stress}

Stress was induced by applying inescapable $0.2 \mathrm{~mA}$ electric foot shock to the rats, as the previously described method (Kim et al., 2015). One set of electric foot shock composed of 6-sec duration and repeated 10 times with 30-sec interval. The rats in the stress-induced groups received three sets of electric foot shock per day. Exposure of rats to the electric foot shock continued for 7 days.

\section{Exercise protocol}

The rats in the exercise groups were forced to run on a motorized treadmill for 30 min once a day for 4 weeks, stating 1 day after last electric food shock. The exercise load consisted of running at a speed of $5 \mathrm{~m} / \mathrm{min}$ for the first $5 \mathrm{~min}, 8 \mathrm{~m} / \mathrm{min}$ for the next 5 $\mathrm{min}$, and $15 \mathrm{~m} / \mathrm{min}$ for the last $20 \mathrm{~min}$, with a $0^{\circ}$ inclination.

\section{Open field test}

For the locomotor activity, open field test was conducted, as the previous described method (Kim et al., 2011). The animals were randomly assigned to an order of testing and placed in a white square open field arena $(100 \times 100 \mathrm{~cm})$ made of wood. It was enclosed with 40-cm-high walls and placed under strong illumination (200 lux). The arena was divided into 25 squares (each square is $20 \times 20 \mathrm{~cm}$ ), defined as 9 central and 16 peripheral squares. The animal was placed in the center of the arena and left free to explore the environment for $1 \mathrm{~min}$. After that time, the number of squares that the rat crossed was recorded for $5 \mathrm{~min}$.

\section{Elevated plus-maze test}

Anxiety-like behaviors were evaluated using the elevated plusmaze test, as the previous described method (Kung et al., 2010; Sterley et al., 2011). The elevated plus-maze test consisted of two opposing open arms $(45 \times 10 \mathrm{~cm})$ and two closed arms $(45 \times 10 \times$ $50 \mathrm{~cm})$ that extended from a central platform $(10 \times 10 \mathrm{~cm})$ elevated $65 \mathrm{~cm}$ above the floor. Each rat was placed on the central platform facing a closed arm, and was allowed to freely explore the maze for $5 \mathrm{~min}$. Entry into an arm was defined as entry of all four paws into the arm. The time spent in the open arms and the percentage of the entries in the open arms during 5 min was calculated.

\section{Tissue preparation}

The animals were sacrificed immediately after finishing open field test. The animals were anesthetized using ethyl ether after which the rats were transcardially perfused with $50 \mathrm{mM}$ phosphate-buffered saline (PBS), and fixed with a freshly prepared solution consisting of $4 \%$ paraformaldehyde in $100 \mathrm{mM}$ phosphate buffer $(\mathrm{pH}, 7.4)$. The brains were dissected and post-fixed in the same fixative overnight and transferred into a 30\% sucrose solution for cryoprotection. Coronal sections of $40 \mu \mathrm{m}$ thickness were made with a freezing microtome (Leica, Nussloch, Germany).

\section{Immunohistochemistry for c-Fos and nNOS}

Immunohistochemistry for c-Fos-positive and nNOS-positive cells in the hypothalamus (Bregma -1.80 to $-1.92 \mathrm{~mm}$ ) and locus coeruleus (Bregma -9.84 to $-9.96 \mathrm{~mm}$ ) was conducted, as the previous described method (Seo et al., 2013; Sim et al., 2008). The sections were incubated in PBS for $10 \mathrm{~min}$, and then washed three 
times in the same buffer. The sections were then incubated in $1 \%$ $\mathrm{H}_{2} \mathrm{O}_{2}$ for $30 \mathrm{~min}$. Next, the sections were incubated overnight with rabbit anti-c-Fos antibody (1:500; Santa Cruz Biotechnology, Santa Cruz, CA, USA) or mouse anti-nNOS antibody (1:500; BD Biosciences, San Jose, CA, USA). The sections were then incubated for $1 \mathrm{hr}$ with anti-rabbit secondary antibody (1:200; Vector Laboratories, Burlingame, CA, USA) for c-Fos immunohistochemistry and with anti-mouse secondary antibody (1:200; Vector Laboratories) for nNOS immunohistochemistry. Next, the sections were incubated with avidin-biotin-peroxidase complex (1:100; Vector Laboratories) for $1 \mathrm{hr}$ at room temperature. For staining, the sections were incubated in solution consisting of $0.02 \% \mathrm{DAB}$ and $0.03 \% \mathrm{H}_{2} \mathrm{O}_{2}$ in $50 \mathrm{mM}$ Tris- $\mathrm{HCl}(\mathrm{pH}, 7.6)$ for approximately $5 \mathrm{~min}$, after which they were washed with PBS and mounted onto gelatin-coated slides. The numbers of c-Fos and nNOS-positive cells in the hypothalamus and locus coeruleus were counted using a light microscope (Olympus, Tokyo, Japan).

\section{Statistical analysis}

The results are presented as the mean \pm standard error of the mean. For comparisons among the groups, one-way analysis of variance and Duncan post hoc test were performed with $P<0.05$ as indication of statistical significance.

\section{RESULTS}

\section{Anxiety-like behaviors}

The effect of treadmill exercise on locomotor activity is presented in Fig. 1a, b. Activity in the inner zone was decreased in the stress-induced group compared to the control group $(P<0.05)$. Treadmill exercise increased activity both in the control group and in the stress-induced group $(P<0.05)$.
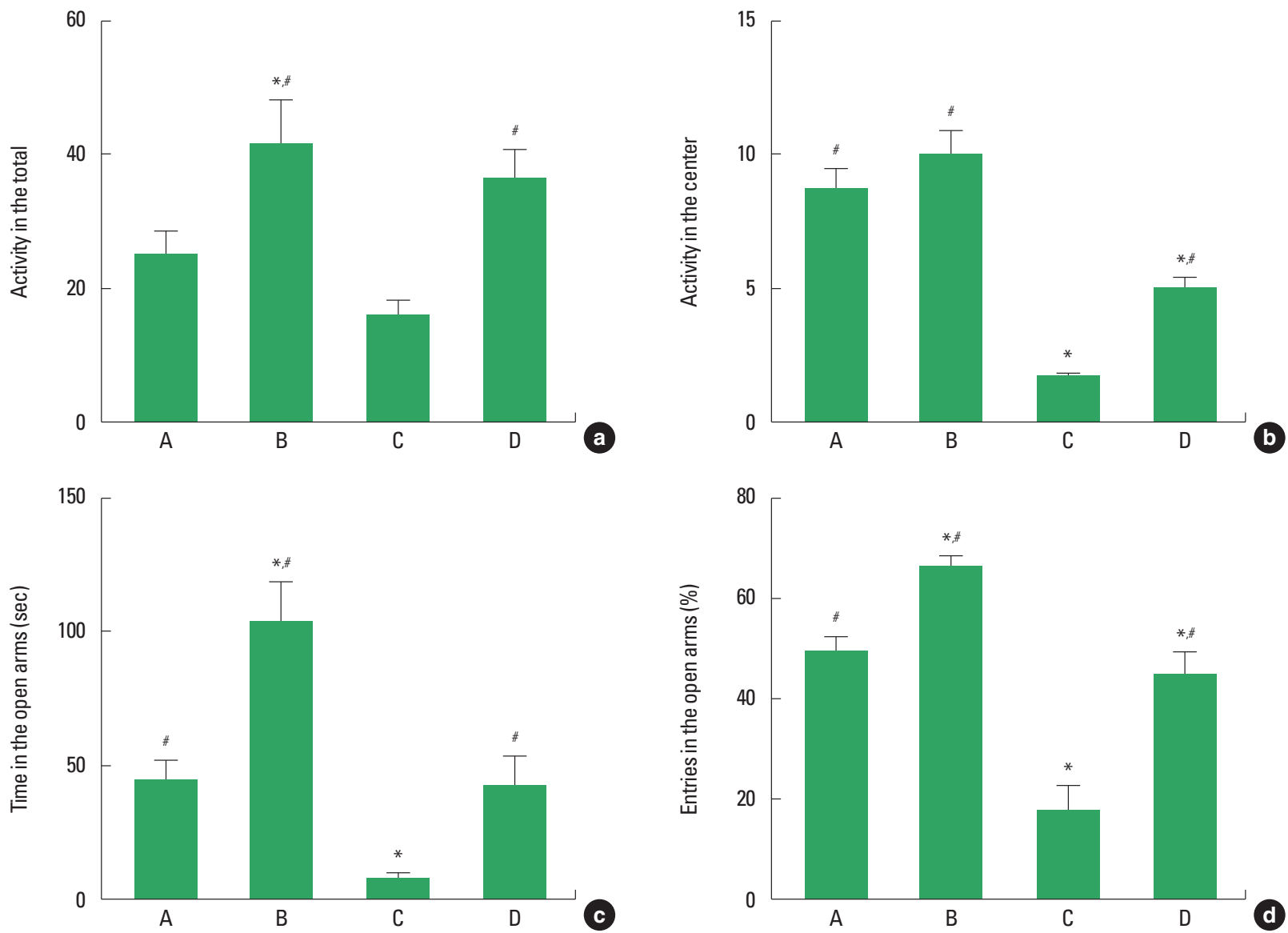

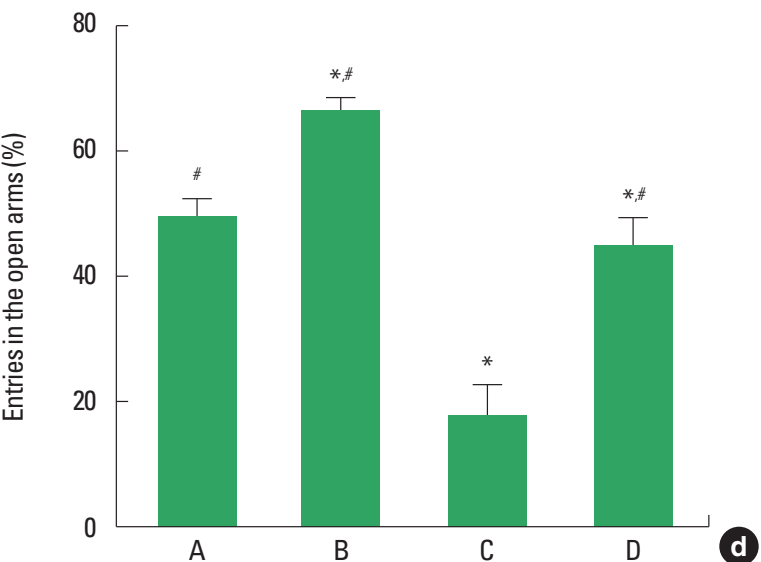

Fig. 1. Effect of treadmill exercise on anxiety-like behaviors in the open field test and in the elevated plus-maze test. (a) Activity in the total of the open field test. (b) Activity in the center zone of the open field test. (c) Time spent in the open arms of the elevated plus maze test. (d) The percentage in the open arm entries of the elevated plus-maze test. A, control group; B, exercise group; $C$, stress-induced group; $\mathrm{D}$, stress-induced and exercise group. ${ }^{*} P<0.05$ compared to the control group. ${ }^{\#} P<0.05$ compared to the stress-induced group. 
The effect of treadmill exercise on anxiety-like behaviors is presented in Fig. 1c, d. The time spent in the open arms and the percentage of the entries in the open arms was lower in the stress- induced group compared to the control group $(P<0.05)$. Treadmill exercise increased time spent and the percentage of the entries both in the control group and in the stress-induced group $(P<0.05)$.

\section{Expressions of c-Fos and nNOS in the hypothalamus}

The number of c-Fos-positive cells in the hypothalamus was presented in Fig. 2. c-Fos expression in the hypothalamus was increased in the stress induced group compared to the control group $(P<0.05)$. Treadmill exercise suppressed c-Fos expression in the hypothalamus of the stress induced group $(P<0.05)$.
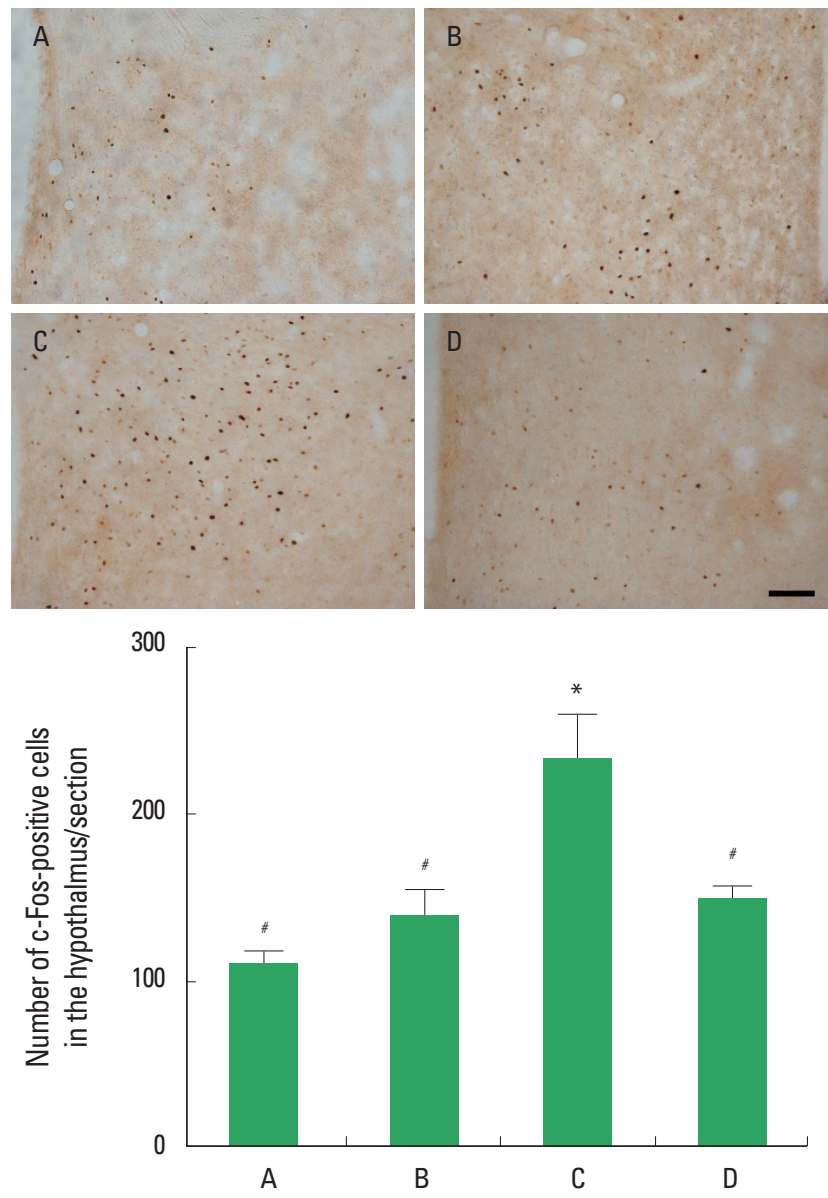

Fig. 2. Effect of treadmill exercise on c-Fos expression in the hypothalamus. Upper panel: Photomicrographs of c-Fos-positive cells in the hypothalamus. The scale bars represent $50 \mu \mathrm{m}$. Lower panel: Number of c-Fos-positive cells in the hypothalamus. A, control group; $B$, exercise group; $C$, stress-induced group; $D$, stress-induced and exercise group. ${ }^{*} P<0.05$ compared to the control group. ${ }^{\#} P<0.05$ compared to the stress-induced group.
The number of nNOS positive cells in the hypothalamus was presented in Fig. 3. nNOS expression in the hypothalamus was increased in the stress induced group compared to the control group $(P<0.05)$. Treadmill exercise exerted no significant effect on $\mathrm{nNOS}$ expression in the hypothalamus of the stress induced group $(P>0.05)$.

\section{Expressions of c-Fos and nNOS in the locus coeruleus}

The number of c-Fos-positive cells in the locus coeruleus was presented in Fig. 4. c-Fos expression in the locus coeruleus was increased in the stress induced group compared to the control group $(P<0.05)$. Treadmill exercise suppressed c-Fos expression in the locus coeruleus of the stress induced group $(P<0.05)$.
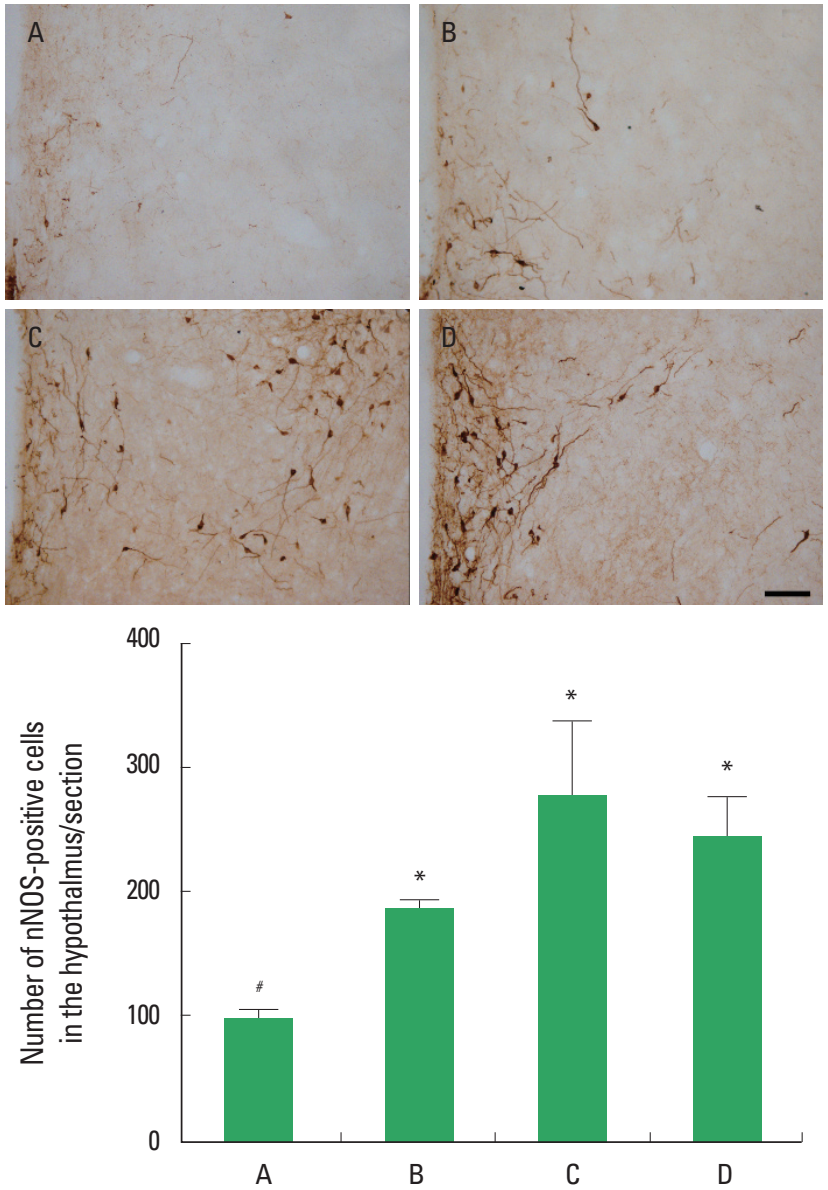

Fig. 3. Effect of treadmill exercise on neuronal nitric oxide synthase (nNOS) expression in the hypothalamus. Upper panel: Photomicrographs of nNOS-positive cells in the hypothalamus. The scale bars represent $50 \mu \mathrm{m}$. Lower panel: Number of nNOS-positive cells in the hypothalamus. A, control group; B, exercise group; $C$, stress-induced group; $D$, stress-induced and exercise group. ${ }^{*} P<0.05$ compared to the control group. ${ }^{*} P<0.05$ compared to the stress-induced group. 

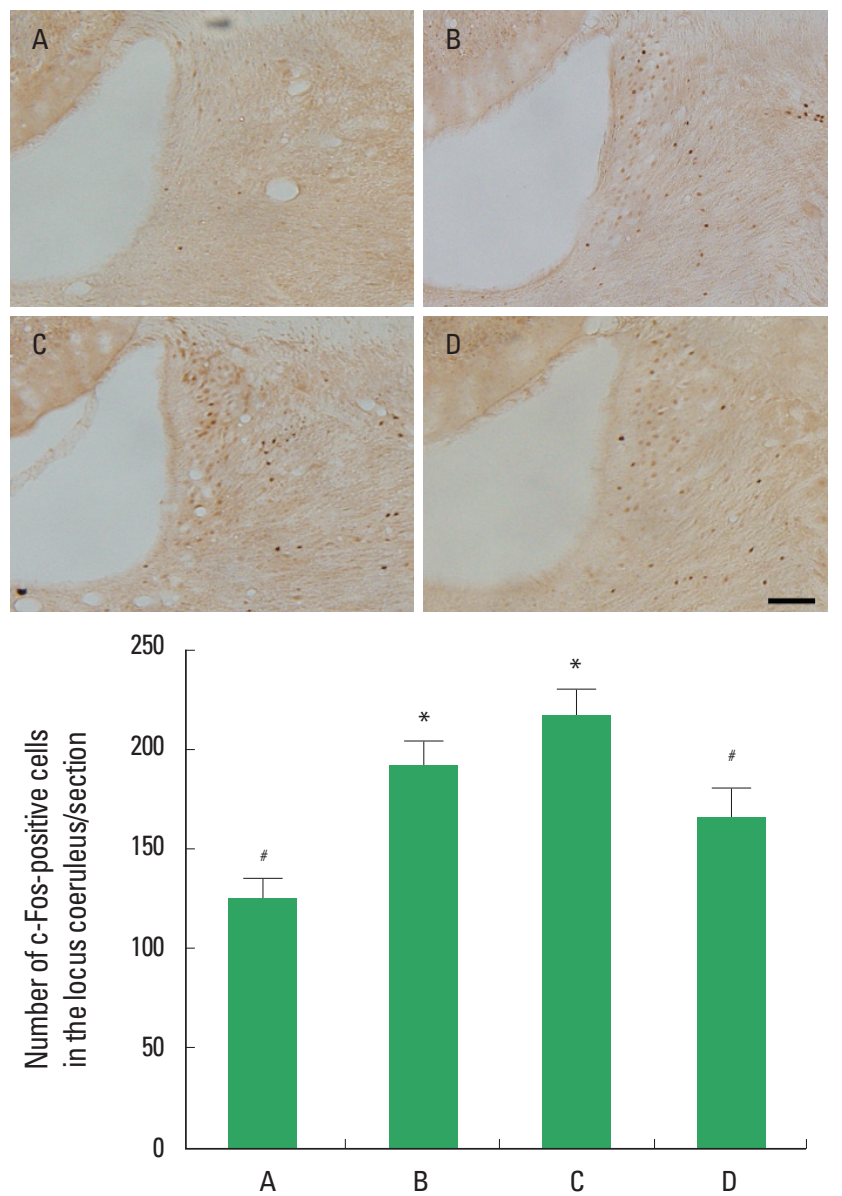

Fig. 4. Effect of treadmill exercise on c-Fos expression in the locus coeruleus. Upper panel: Photomicrographs of c-Fos-positive cells in the locus coeruleus. The scale bars represent $50 \mu \mathrm{m}$. Lower panel: Number of c-Fos-positive cells in the locus coeruleus. A, control group; $B$, exercise group; $C$, stress-induced group; $D$, stress-induced and exercise group. ${ }^{*} P<0.05$ compared to the control group. ${ }^{\#} P<0.05$ compared to the stress-induced group.

The number of nNOS positive cells in the locus coeruleus was presented in Fig. 5. nNOS expression in the locus coeruleus was increased in the stress induced group compared to the control group $(P<0.05)$. Treadmill exercise suppressed c-Fos expression in the locus coeruleus of the stress induced group $(P<0.05)$.

\section{DISCUSSION}

Newman and Matta (2007) reported that aerobic exercise reduced childhood posttraumatic stress disorder (PTSD), depression, and anxiety. Anxiolytic effect of exercise is well documented (Asmundson et al., 2013; Merom et al., 2008). The distance traveled in the open field test is a common measure of exploratory and spontaneous locomotor activity in rodents (Verma et al., 2010;
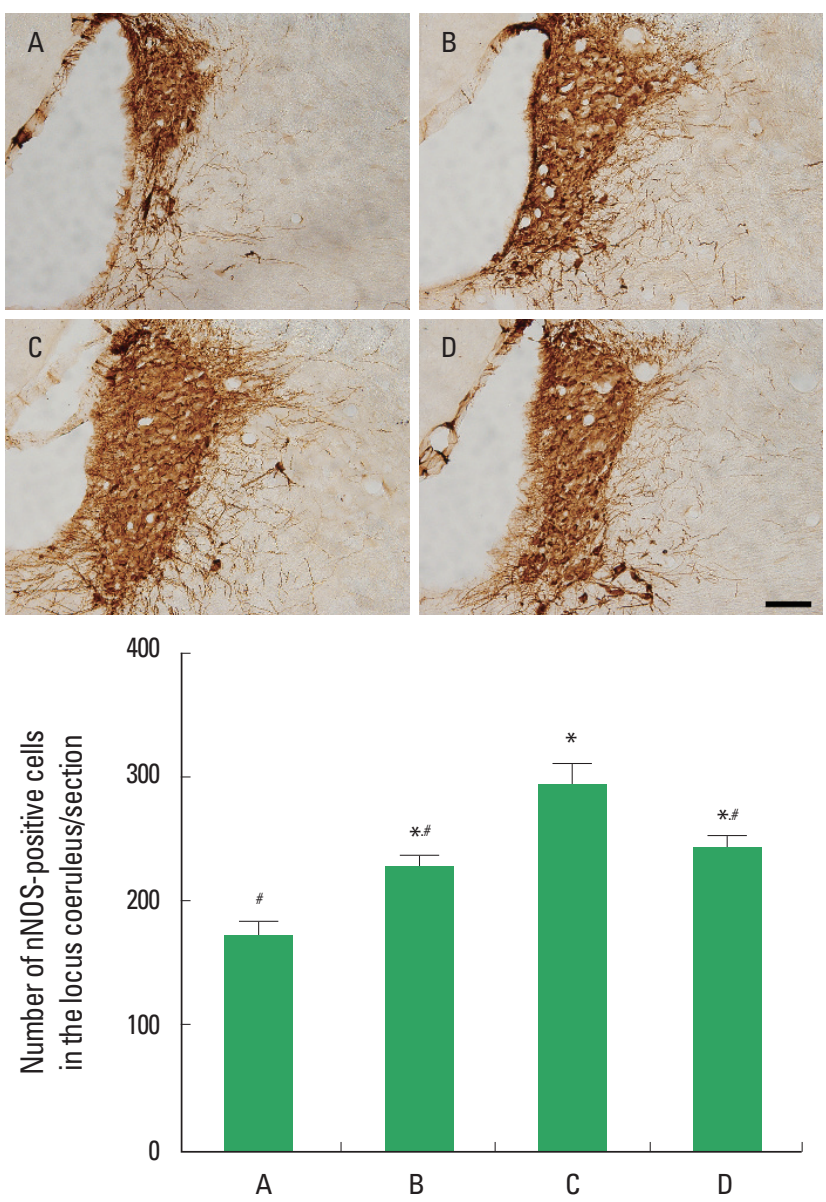

Fig. 5. Effect of treadmill exercise on neuronal nitric oxide synthase (nNOS) expression in the locus coeruleus. Upper panel: Photomicrographs of nNOS-positive cells in the locus coeruleus. The scale bars represent $50 \mu \mathrm{m}$. Lower panel: Number of nNOS-positive cells in the locus coeruleus. A, control group; B, exercise group; $C$, stress-induced group; $D$, stress-induced and exercise group. ${ }^{*} P<0.05$ compared to the control group. ${ }^{*} P<0.05$ compared to the stress-induced group.

Zhao et al., 2016). The rats with anxiety spent a lot of time in the open field test (Seibenhener and Wooten, 2015). The elevated plus-maze reflects passive avoidance of an animal in response to a potential threat and has become a very popular approach for the evaluation of anxiety behaviors by assessing the number of open arm entries as well as the time spent in open arms (Lister, 1987). Long-term treadmill running in rats reduced anxiety-like behaviors in the elevated plus-maze test (Fulk et al., 2004).

In the present study, locomotor activity in the center of the open field test and the number of entries and time in the open arms of the elevated plus-maze test were reduced in the rats with stress-induced anxiety. Treadmill running enhanced the locomotor activity with the number of entries and time in the stress-induced anxiety rats. 
Expression of c-Fos following stress is highly region-specific, including the paraventricular nucleus and locus coeruleus, and c-Fos expression is involved in the adaptation to social stress (Martinez et al., 1998). c-Fos expression in the paraventricular nucleus and locus coeruleus was increased by single restraint, and this increment was attenuated by repeated restraint stress (Kwon et al., 2006). c-Fos expression represents neuronal activity and plays a crucial role in the brain development (Sim et al., 2008). Restraint stress enhances c-Fos expression in the paraventricular nucleus, locus coeruleus, supraoptic nucleus, rostral raphe pallidus, nucleus of the solitary tract and ventrolateral medulla (Goebel et al., 2009). Treadmill exercise decreased the expression of c-Fos in the PTSD-induced rats, indicating that treadmill exercise during pregnancy suppressed neuronal activation induced by the stress exposure (Seo et al., 2013).

In the present study, c-Fos expression in the hypothalamus and locus coeruleus was increased in the stress-induced rats. Treadmill exercise reduced c-Fos overexpression in the stress-induced rats. The present results demonstrated that treadmill exercise alleviated the stress-induced c-Fos expression.

Inhibition of nNOS altered social interactions and decreased anxiety-like behaviors (Forestiero et al., 2006). Inhibition of nNOS signaling in the brain may be a novel approach for the treatment of depressive disorders (Zhou et al., 2007). Inhibition of NOS caused antidepressive effect (Jesse et al., 2008; Seo et al., 2013).

In the present study, nNOS expression in the hypothalamus and locus coeruleus was increased in the stress-induced rats. Treadmill exercise reduced $\mathrm{nNOS}$ overexpression in the stress-induced rats. The present results demonstrated that treadmill exercise alleviated the stress-induced $\mathrm{nNOS}$ expression.

The present results showed that treadmill exercise ameliorated anxiety-like behaviors in the stress-induced rats. This effect of treadmill exercise on anxiety-like behaviors might be ascribed to the suppressing effect of exercise on c-Fos and nNOS expressions.

\section{CONFLICT OF INTEREST}

No potential conflict of interest relevant to this article was reported.

\section{ACKNOWLEDGMENTS}

This research is supported by 2018 Baekseok University Research fund.

\section{REFERENCES}

Adhikari A. Distributed circuits underlying anxiety. Front Behav Neurosci 2014;8:112

Asmundson GJ, Fetzner MG, Deboer LB, Powers MB, Otto MW, Smits JA. Let's get physical: a contemporary review of the anxiolytic effects of exercise for anxiety and its disorders. Depress Anxiety 2013;30:362373.

Berridge CW, Waterhouse BD. The locus coeruleus-noradrenergic system: modulation of behavioral state and state-dependent cognitive processes. Brain Res Brain Res Rev 2003;42:33-84.

Borodovitsyna O, Flamini MD, Chandler DJ. Acute stress persistently alters locus coeruleus function and anxiety-like behavior in adolescent rats. Neuroscience 2018;373:7-19.

Forestiero D, Manfrim CM, Guimarães FS, de Oliveira RM. Anxiolyticlike effects induced by nitric oxide synthase inhibitors microinjected into the medial amygdala of rats. Psychopharmacology (Berl) 2006; 184:166-172.

Fulk LJ, Stock HS, Lynn A, Marshall J, Wilson MA, Hand GA. Chronic physical exercise reduces anxiety-like behavior in rats. Int J Sports Med 2004;25:78-82.

Goebel M, Stengel A, Wang L, Taché Y. Restraint stress activates nesfatin-1-immunoreactive brain nuclei in rats. Brain Res 2009;1300:114124.

Herman JP, Tasker JG. Paraventricular hypothalamic mechanisms of chronic stress adaptation. Front Endocrinol (Lausanne) 2016;7:137.

Hovland A, Nordhus IH, Sjøbø T, Gjestad BA, Birknes B, Martinsen EW, Torsheim T, Pallesen S. Comparing physical exercise in groups to group cognitive behaviour therapy for the treatment of panic disorder in a randomized controlled trial. Behav Cogn Psychother 2013;41:408432.

Imaki T, Katsumata H, Konishi SI, Kasagi Y, Minami S. Corticotropin-releasing factor type- 1 receptor mRNA is not induced in mouse hypothalamus by either stress or osmotic stimulation. J Neuroendocrinol 2003;15:916-924.

Jesse CR, Bortolatto CF, Savegnago L, Rocha JB, Nogueira CW. Involvement of L-arginine-nitric oxide-cyclic guanosine monophosphate pathway in the antidepressant-like effect of tramadol in the rat forced swimming test. Prog Neuropsychopharmacol Biol Psychiatry 2008;32:18381843.

Kim H, Heo HI, Kim DH, Ko IG, Lee SS, Kim SE, Kim BK, Kim TW, Ji ES, Kim JD, Shin MS, Choi YW, Kim CJ. Treadmill exercise and methylphenidate ameliorate symptoms of attention deficit/hyperactivity disorder through enhancing dopamine synthesis and brain-derived neurotrophic factor expression in spontaneous hypertensive rats. Neuros- 
ci Lett 2011;504:35-39.

Kim TW, Lim BV, Baek D, Ryu DS, Seo JH. Stress-induced depression is alleviated by aerobic exercise through up-regulation of 5-hydroxytryptamine 1A receptors in rats. Int Neurourol J 2015;19:27-33.

Kung JC, Chen TC, Shyu BC, Hsiao S, Huang AC. Anxiety- and depressivelike responses and c-fos activity in preproenkephalin knockout mice: oversensitivity hypothesis of enkephalin deficit-induced posttraumatic stress disorder. J Biomed Sci 2010;17:29.

Kwon MS, Seo YJ, Shim EJ, Choi SS, Lee JY, Suh HW. The effect of single or repeated restraint stress on several signal molecules in paraventricular nucleus, arcuate nucleus and locus coeruleus. Neuroscience 2006; 142:1281-1292.

Lister RG. The use of a plus-maze to measure anxiety in the mouse. Psychopharmacology (Berl) 1987;92:180-185.

Martinez M, Phillips PJ, Herbert J. Adaptation in patterns of c-fos expression in the brain associated with exposure to either single or repeated social stress in male rats. Eur J Neurosci 1998;10:20-33.

Merom D, Phongsavan P, Wagner R, Chey T, Marnane C, Steel Z, Silove D, Bauman A. Promoting walking as an adjunct intervention to group cognitive behavioral therapy for anxiety disorders: a pilot group randomized trial. J Anxiety Disord 2008;22:959-968.

Miguel TT, Nunes-de-Souza RL. Anxiogenic-like effects induced by NMDA receptor activation are prevented by inhibition of neuronal nitric oxide synthase in the periaqueductal gray in mice. Brain Res 2008;1240:39-46.

Minatohara K, Akiyoshi M, Okuno H. Role of immediate-early genes in synaptic plasticity and neuronal ensembles underlying the memory trace. Front Mol Neurosci 2016;8:78.

Myers B, Scheimann JR, Franco-Villanueva A, Herman JP. Ascending mechanisms of stress integration: implications for brainstem regulation of neuroendocrine and behavioral stress responses. Neurosci Biobehav Rev 2017;74(Pt B):366-375.

Newman CL, Motta RW. The effects of aerobic exercise on childhood PTSD, anxiety, and depression. Int J Emerg Ment Health 2007;9:133-
158.

Ploski JE, Monsey MS, Nguyen T, DiLeone RJ, Schafe GE. The neuronal PAS domain protein 4 (Npas4) is required for new and reactivated fear memories. PLoS One 2011;6:e23760.

Seibenhener ML, Wooten MC. Use of the Open Field Maze to measure locomotor and anxiety-like behavior in mice. J Vis Exp 2015;(96):e52434.

Seo JH, Kim TW, Kim CJ, Sung YH, Lee SJ. Treadmill exercise during pregnancy ameliorates post traumatic stress disorder induced anxiety like responses in maternal rats. Mol Med Rep 2013;7:389-395.

Sherwin E, Gigliucci V, Harkin A. Regional specific modulation of neuronal activation associated with nitric oxide synthase inhibitors in an animal model of antidepressant activity. Behav Brain Res 2017;316:18-28.

Sim YJ, Kim H, Shin MS, Chang HK, Shin MC, Ko IG, Kim KJ, Kim TS, Kim BK, Rhim YT, Kim S, Park HY, Yi JW, Lee SJ, Kim CJ. Effect of postnatal treadmill exercise on c-Fos expression in the hippocampus of rat pups born from the alcohol-intoxicated mothers. Brain Dev 2008; 30:118-125.

Sterley TL, Howells FM, Russell VA. Effects of early life trauma are dependent on genetic predisposition: a rat study. Behav Brain Funct 2011;7:11.

Verma P, Hellemans KG, Choi FY, Yu W, Weinberg J. Circadian phase and sex effects on depressive/anxiety-like behaviors and HPA axis responses to acute stress. Physiol Behav 2010;99:276-285.

Workman JL, Trainor BC, Finy MS, Nelson RJ. Inhibition of neuronal nitric oxide reduces anxiety-like responses to pair housing. Behav Brain Res 2008;187:109-115.

Zhao TT, Shin KS, Kim KS, Park HJ, Kim HJ, Lee KE, Lee MK. Effects of (-)-sesamin on motor and memory deficits in an MPTP-lesioned mouse model of Parkinson's disease treated with l-DOPA. Neuroscience 2016; 339:644-654.

Zhou QG, Hu Y, Hua Y, Hu M, Luo CX, Han X, Zhu XJ, Wang B, Xu JS, Zhu DY. Neuronal nitric oxide synthase contributes to chronic stressinduced depression by suppressing hippocampal neurogenesis. J Neurochem 2007;103:1843-1854. 